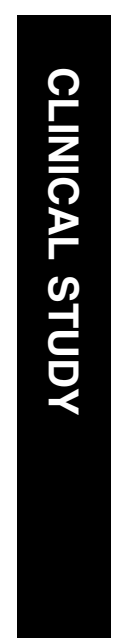

\title{
Non-invasive biometric assessment of ocular rigidity in glaucoma patients and controls
}

Department of

Ophthalmology, Cantonal Hospital St Gallen, St Gallen, Switzerland

Correspondence:

Dr med A Ebneter, Augenklinik Kantonsspital, Rorschacherstrasse 95,

St Gallen,

$\mathrm{CH}-9007$

Switzerland

Tel: +4171 49417 71;

Fax: + 41714942881 .

E-mail: ebneter.andreas@

gmail.com

Received: 22 October 2007 Accepted in revised form: 29 January 2008

Published online: 29

February 2008

\begin{abstract}
Purpose To determine in vivo whether a pharmacologically induced change in intraocular pressure (IOP) leads to measurable changes in axial eye length and whether there is a difference between glaucoma patients and control subjects.

Methods 42 subjects (19 patients with primary open angle glaucoma and 23 control patients matched for age and gender) underwent axial eye length measurement using partial coherence laser interferometry and measurement of IOP using dynamic contour tonometry before and $2 \mathrm{~h}$ after oral intake of $500 \mathrm{mg}$ acetazolamide. Student's $t$-test was used to compare differences in the means.

Results An identical drop in IOP was induced in both the glaucoma (mean \pm SEM: $2.90 \pm 0.44 \mathrm{mmHg}, n=19)$ and the control group (mean \pm SEM: $3.17 \pm 0.32 \mathrm{mmHg}, n=23$ ). The change in axial eye length was significantly smaller $(P=0.026)$ in the glaucoma group (mean \pm SEM: $-14.2 \pm 3.2 \mu \mathrm{m}$, $n=19)$ compared with the control group (mean \pm SEM: $-23.0 \pm 2.98 \mu \mathrm{m}, n=23$ ). Conclusions Our results strongly suggest that the ocular rigidity is increased in patients with established glaucoma in comparison to control subjects. Ocular rigidity could play a role in the pathogenesis and pathophysiology of glaucoma. Determination of ocular rigidity could be helpful in detection of glaucoma.

Eye (2009) 23, 606-611; doi:10.1038/eye.2008.47; published online 29 February 2008
\end{abstract}

Keywords: ocular rigidity; axial eye length; primary open angle glaucoma; partial coherence laser interferometry
A Ebneter, B Wagels and MS Zinkernagel

\section{Introduction}

Ocular rigidity is a biomechanical parameter of the eye expressing the elasticity of the globe. It depends mainly on the properties of the cornea, sclera and other components of the outer shell of the eye. Ocular rigidity relates intraocular pressure changes to the corresponding volume changes and is a measure of the resistance that the eye exerts to distending forces. ${ }^{1}$ Probably the most commonly used pressure-volume relationship is that developed by Friedenwald. ${ }^{2}$ This formula is based on measurements performed on cadaver eyes. A more sophisticated model has been proposed by Silver et al. ${ }^{3}$ This group derived the pressurevolume relation by numerical experimentation using all previously published rigidity measurements on living human eyes. The formula took the form $\Delta \mathrm{V}=\mathrm{V} \times\left(\mathrm{C}+\mathrm{C}_{0} \times \ln \mathrm{P}\right.$ $\left.+\mathrm{C}_{1} \times \mathrm{P}\right) . \Delta \mathrm{V}$ is the increment of volume over an arbitrary reference volume. $\mathrm{V}$ is the volume of the eye. $\mathrm{P}$ is the intraocular pressure. The numerical parameters $C\left(=-8.03 \times 10^{-3}\right), \mathrm{C}_{0}$ $\left(=4.87 \times 10^{-3}\right)$ and $\mathrm{C}_{1}\left(=3.90 \times 10^{-5} \mathrm{mmHg}^{-1}\right)$ have been determined by least-square fitting of a polynomial function to the rigidity measurements.

Ocular rigidity is influenced by many factors. Marked differences were seen when the ocular rigidity measured on living eyes was compared with the ocular rigidity measured on the same eyes after enucleation. Ocular rigidity of enucleated eyes is higher than that in living human eyes. The difference seems to arise from choroidal blood flow. ${ }^{4-6}$ It is therefore essential to perform in vivo measurements. Ocular rigidity is inversely proportional to the eye volume. ${ }^{7}$ In myopic eyes rigidity is decreased, whereas in hyperopic eyes it is increased. On the other hand, ocular rigidity is directly 
proportional to intraocular pressure. ${ }^{6,8}$ In a higher pressure state, it is more elevated than in a lower pressure state. A recent study by Pallikaris et al ${ }^{9}$ showed a positive correlation between the ocular rigidity coefficient and age. Ocular rigidity seems to be altered in long-standing glaucoma. ${ }^{10}$ There is an ongoing debate on the role of ocular rigidity in the pathogenesis of myopia and age-related macular degeneration. Although several studies evaluated these topics, results remain controversial. ${ }^{11-13}$

An established way of measuring ocular rigidity in living eyes is by injecting small-volume increments into the anterior chamber and measuring the resulting pressure change. ${ }^{9}$ However, this is an invasive method and not suitable for everyday clinical practice.

Furthermore, concerns have been raised regarding accuracy of this method because of the valve effect of the iris-lens diaphragm. ${ }^{14,15}$

The intraocular volume and its changes are not directly measurable by simple means. However, axial length certainly contributes to the overall size of the eye and may even be the determining factor. Consequently, changes in axial length due to intraocular pressure (IOP) changes should be influenced by ocular rigidity. Axial length can easily and precisely be measured. ${ }^{16-18}$ Several studies have shown a decrease of axial eye length with lowered intraocular pressure after trabeculectomy. ${ }^{19-22} \mathrm{~A}$ recent study by Leydolt et $a l^{23}$ measured the change of axial eye length after mechanically inducing intraocular pressure elevation.

The aim of this study was to investigate the effect of pharmacologically induced short-term IOP lowering on the axial length in emmetropic eyes and to assess differences between eyes with primary open-angle glaucoma and healthy eyes.

\section{Materials and methods}

The study was performed according to the tenets of the Declaration of Helsinki and approved by the ethics committee of the Canton of St Gallen. Informed consent was obtained from all subjects in this study after the nature and possible consequences of the study had been explained. Before inclusion, each subject passed an ophthalmic evaluation consisting of a medical history, a slit lamp examination and a biomicroscopic inspection of the optic disc and the central retina.

Inclusion criteria for patients with glaucoma were a repeatable abnormal visual field in the examination program G2 (Cupola Perimeter Octopus 101, Haag Streit, Köniz, Switzerland) and at least two documented IOP measurements of $>22 \mathrm{mmHg}$. Healthy eyes were defined as those with healthy-appearing optic discs on biomicroscopic examination and no history of IOP
$>22 \mathrm{mmHg}$. Exclusion criteria in both groups included any contraindication to the use of acetazolamide, any previous incisional surgery, narrow angle in gonioscopy, any form of secondary glaucoma, corneal anomalies, myopia of more than -2.0 diopters spherical equivalent or hyperopia of more than +1.0 diopter spherical equivalent.

We included 42 eyes of 42 subjects in this prospective comparative clinical trial. Control subjects were matched for gender and age to within 5 years. Only one eye per subject was included. In the control group, we always considered the right eye. In the glaucoma group, we primarily included the eye fulfilling the inclusion criteria. If both eyes qualified, we included the one showing more advanced glaucomatous damage in terms of visual field changes.

Axial eye length, defined as the distance from the anterior corneal surface to the retinal pigment epithelium along the visual axis using a red fixation beam, was measured with the commercially available IOL Master (Zeiss Meditec, Jena, Germany) using partial coherence laser interferometry. In measuring axial eye length, the IOL Master is reported to have a resolution of about $10 \mu \mathrm{m}$ and a precision of $5 \mu \mathrm{m} .{ }^{24}$ Five single measurements were obtained for each eye through an undilated pupil with the patient in a sitting position. The mean was calculated by the IOL Master. Axial eye length was always measured before IOP.

Intraocular pressure measurements were obtained by using dynamic contour tonometry (PASCAL Dynamic Contour Tonometer, Ziemer Ophthalmic Systems AG, Port, Switzerland). The influence of central corneal thickness and other corneal parameters on IOP readings are minimized using this method. ${ }^{25}$ Before each measurement, one drop of proxymetacaine (Alcaine, Alcon, Switzerland) was instilled into the conjunctival sac for local anaesthesia. Only records with a goodquality index (Q1 or Q2) were taken into account.

Intraocular pressure was decreased pharmacologically by $500 \mathrm{mg}$ acetazolamide. Baseline measurements of axial eye length, IOP, blood pressure and arterial pulse were taken at the beginning of the examination. Thereafter, two tablets of Diamox ( $250 \mathrm{mg}$ ) were swallowed by the examinee in the presence of the examiner. Axial length, IOP, blood pressure and arterial pulse were measured again $2 \mathrm{~h}$ later. It has previously been shown that maximal IOP lowering is reached $2 \mathrm{~h}$ after oral administration. ${ }^{26}$ Finally, central corneal thickness was assessed using ultrasonic pachymetry (300P Pacscan Pachymeter, Sonomed Inc., Lake Success, NY, USA).

Throughout the text, data are presented as mean value \pm SEM. The Student's $t$-tests for independent samples was used to compare the means, considering $P<0.05$ for statistical significance. Statistical analysis was 
Table 1 Baseline characteristics and induced IOP change

\begin{tabular}{lccc}
\hline Characteristic & Glaucoma group $(\mathrm{n}=19)$ & Control subjects $(\mathrm{n}=23)$ & P-value (t-test) \\
\hline Male subjects (number) & $8(42 \%)$ & $11(48 \%)$ & 0.719 \\
Age (years) & $64.6(61.4-67.8)$ & $64.5(61.9-67.1)$ & 0.955 \\
Axial length $(\mathrm{mm})$ & $23.70(23.10-24.30)$ & $23.57(23.14-24.00)$ & 0.701 \\
Corneal thickness $(\mu \mathrm{m})$ & $546(527-564)$ & $542(527-556)$ & 0.717 \\
Initial IOP $(\mathrm{mmHg})$ & $18.3(17.1-19.6)$ & $16.2(15.1-17.3)$ & 0.009 \\
IOP drop $(\mathrm{mmHg})$ & $2.9(2.0-3.8)$ & $3.2(2.5-3.8)$ & 0.611 \\
IOP drop $(\%)$ & $15.8(10.6-21.0)$ & $19.2(16.0-22.4)$ & 0.238 \\
\hline
\end{tabular}

Except for gender, data are presented as mean value and $95 \%$ confidence interval.

performed with Prism 4 for Windows (GraphPad Software Inc., San Diego, CA, USA).

\section{Results}

Nineteen eyes suffering from primary open-angle glaucoma were included in the glaucoma group $(n=19$, mean age 64.6 years, range $52-74)$. The control group consisted of 23 healthy eyes $(n=23$, mean age 64.5 years, range 54-76). Except for initial IOP, the baseline characteristics in the two groups were identical (Table 1). Acetazolamide led to an identical drop of IOP in both groups $(P=0.61) 2 \mathrm{~h}$ after oral intake. In the glaucomatous eyes, the IOP fell by $2.90 \pm 0.44 \mathrm{mmHg}$ (mean $\pm \mathrm{SEM}, n=19$ ), corresponding to a $16 \%$ reduction. In the control subjects, the intraocular pressure diminished by $3.17 \pm 0.32 \mathrm{mmHg}$ (mean $\pm \mathrm{SEM}, n=23$ ) or $19 \%$, respectively. Relative pressure lowering in both groups was not statistically different $(P=0.24)$.

In the glaucoma group, the axial length decreased by $14 \pm 3.3 \mu \mathrm{m}$ (mean \pm SEM, $n=19$ ). This decrease is highly statistically significant at a level of $P=0.0004$. In the control population, axial length diminished by $23 \pm 3.0 \mu \mathrm{m}$ (mean \pm SEM, $n=23$ ) at an even more significant level $(P<0.0001)$. In addition, the change in axial length induced by identical lowering of IOP was significantly different between the two groups with $P=0.026$ (Figure 1). Mean axial eye length shortening per $\mathrm{mmHg}$ of IOP decrease was also calculated and was found to be $5.2 \pm 1.5 \mu \mathrm{m} / \mathrm{mmHg}$ (mean $\pm \mathrm{SEM}, n=19$ ) in glaucoma eyes and $9.1 \pm 1.6 \mu \mathrm{m} / \mathrm{mmHg}$ (mean \pm SEM, $n=23)$ in the healthy ones. This difference was also statistically significant $(P=0.047)$.

\section{Discussion}

With pharmacologically induced short-term lowering of IOP after systemic administration of acetazolamide, we found a significant shortening in axial eye length. A decrease in axial eye length due to lowered intraocular pressure has been shown in several previous studies ${ }^{19-23}$ To our knowledge, this is the first study to demonstrate

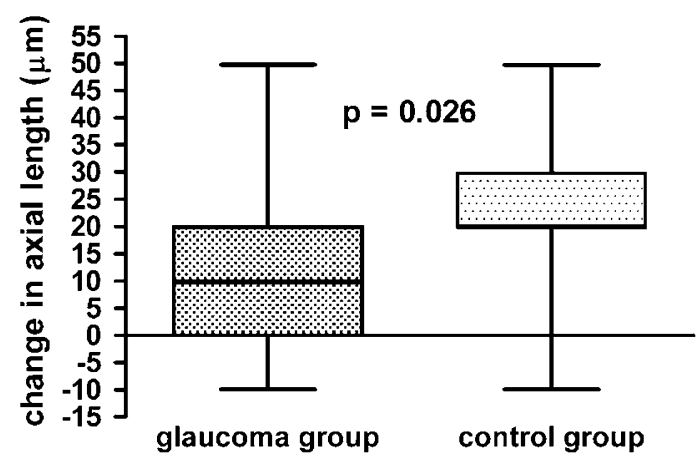

Figure 1 Axial eye length change induced by identical IOP lowering.

this effect after systemic administration of acetazolamide and the first to investigate the difference in rigidity between healthy and glaucomatous eyes in vivo. The resulting axial eye length decrease per $\mathrm{mmHg}$ IOP reduction was smaller for the glaucomatous eyes than for the healthy ones, suggesting that glaucomatous eyes are more rigid. The intraocular volume change resulting from a certain amount of IOP change is dependent on the eyeball's rigidity. In a condition with elevated rigidity, an identical decrease in distending forces would induce a smaller change in dimensions than in a normal eye.

There are several advantages of our method compared with previous studies. Leydolt $e t \mathrm{al}^{23}$ used a suction cup causing mechanical stress and local deformation to the sclera to induce IOP changes. Use of the suction cup could cause deformation of the entire globe, resulting in axial eye length alterations independent of pressure change. We obtained IOP lowering by pharmacological means only without manipulation of the bulbus. We did all the examinations and measurements with undilated pupils.

However, the changes in axial length obtained using acetazolamide were small and very close to the resolution limit of the currently available machines using partial coherence interferometry. Furthermore, it is unknown if there is an effect of acetazolamide on the thickness of the choroid and on scleral rigidity. 
Table 2 Literature overview on pressure-induced axial eye length change

\begin{tabular}{|c|c|c|c|c|c|c|c|c|}
\hline Author & Year & Eyes & Setting & Method & \multicolumn{4}{|c|}{$\begin{array}{l}\text { Time after pressure lowering or surgery } \\
\text { Axial length change per } \mathrm{mm} \mathrm{Hg}(\mu \mathrm{m} / \mathrm{mmHg})\end{array}$} \\
\hline Leydolt $e t a l^{23}$ & 2007 & 18 & Suction cup technique & IOL Master & & $\begin{array}{l}\text { Immedia } \\
2\end{array}$ & & \\
\hline $\begin{array}{l}\text { Kiss B et al } \\
\text { ARVO Abstract } 2379\end{array}$ & 1999 & NA & Timolol $0.5 \%$ & Laser interferometer & & $\begin{array}{c}\text { Hours } \\
6,5\end{array}$ & & \\
\hline Francis BA et $a l^{22}$ & 2005 & 39 & Trabeculectomy & IOL Master & $\begin{array}{c}1 \text { week } \\
20.0\end{array}$ & $\begin{array}{l}1 \text { month } \\
15.6\end{array}$ & & $\begin{array}{c}>3 \text { months } \\
3.9\end{array}$ \\
\hline Francis BA et $a l^{22}$ & 2005 & 22 & Glaucoma drainage device & IOL Master & $\begin{array}{c}1 \text { week } \\
13.5\end{array}$ & $\begin{array}{l}1 \text { month } \\
38.0\end{array}$ & & $\begin{array}{c}>3 \text { months } \\
12.1\end{array}$ \\
\hline Kook et al $l^{20}$ & 2000 & 18 & Trabeculectomy & A-scan biometry & $\begin{array}{cc}1 \text { week } & 1 \text { month } \\
21.9 & 22.1\end{array}$ & $\begin{array}{l}3 \text { months } \\
20.2\end{array}$ & $\begin{array}{c}6 \text { months } \\
19.3\end{array}$ & $\begin{array}{l}12 \text { months } \\
19.1\end{array}$ \\
\hline Cashwell et al ${ }^{19}$ & 1999 & 18 & Glaucoma filtering surgery & A-scan biometry & & $\begin{array}{l}22 \text { months } \\
25.6\end{array}$ & & \\
\hline
\end{tabular}

The observed changes in axial eye length are comparable to existing data already published (Table 2). Leydolt $e a^{23}$ observed changes in axial eye length using the IOL Master in healthy eyes similar to our measurements. This highly precise non-contact technique based on partial laser interferometry was also used by Francis $e a^{22}$ to evaluate axial eye length shortening after glaucoma surgery. Changes turned out to be more pronounced, especially in the early course after surgery. However, the setting was different in that pressure was measured in the long-term course and the structural integrity of the bulbus might be considerably altered by filtering surgery. Three months after surgery, the axial eye length change per $\mathrm{mmHg}$ of pressure decrease was again quite close to our values. The relationship between ocular rigidity and IOP is likely not linear and there might be a threshold of IOP reduction below which significant axial eye length reduction results. In the study by Francis et al, the axial eye length decrease was significantly more important in hypotonous eyes. We guess that normal eyes might even be more prone to considerable length decrease after profound IOP reduction due to lower rigidity. Farther back, Kook et $a l^{20}$ and Cashwell et $a l^{19}$ studied axial eye length changes after filtering glaucoma surgery. In the long-term course (12-22 months), they found shortening of the bulbus of about $20-25 \mu \mathrm{m} / \mathrm{mmHg}$. This is about twice the changes noted by Francis et $a l^{22}$ in a comparable setting. This difference might be due to the fact that A-scan biometry was used by Kook et al. This ultrasound-based method requires direct contact to the cornea during measurement and is likely to induce bias, especially in hypotonous eyes. Moreover, resolution and precision of partial coherence interferometry is known to be about 10 times better than that of ultrasound-based methods. ${ }^{16,24}$

Recent studies using finite element modelling showed that the biomechanical properties of the corneoscleral shell profoundly affect the level of mechanical stress experienced by the optic nerve head $(\mathrm{ONH}) \cdot{ }^{27,28}$ Forces at the ONH have been shown to be up to 180 times IOP. ${ }^{29}$ Several previous studies found ocular rigidity to be increased in glaucomatous eyes. We hypothesize that this might be due to structural changes of the sclera. Tengroth et $a l^{30}$ found changes in the content and composition of collagen fibres in the eyes of glaucoma patients.

Moreover, the prevalence of glaucoma augments with age. ${ }^{31}$ With aging, the connective tissue becomes more rigid due to an increase in the cross-sectional area of the fibrils and an increase in cross-linking. ${ }^{32}$ Thus, to a certain extent, increased rigidity can be seen as a part of the normal aging process. ${ }^{2}$ A very recent nutritional study points to the potential importance of dietary habits. Nguyen et $a l^{33}$ found both decreased IOP and decreased rigidity in the eyes of rats on an omega- 3 polyunsaturated fatty acids-sufficient diet compared with animals on an omega-3 fatty acids-deficient diet.

The question whether the biomechanical changes are a consequence or part of the pathogenesis of the disease is much more delicate. There is pretty good evidence that ocular rigidity is increased in established glaucoma cases. But it might be possible that ocular rigidity changes in the course of the disease. Drance ${ }^{10}$ postulated decreased scleral rigidity in untreated glaucoma patients. Agrawal et $a l^{34}$ found that decreased scleral rigidity rose to almost normal values after topical treatment with timolol or pilocarpine. Downs et $a l^{35}$ noticed increased peripapillary rigidity in monkey eyes in early experimental glaucoma. In our cross-sectional study, the diagnosis of glaucoma was well established, most patients had topical pressure-lowering treatment and all showed signs of axonal damage. To address the issue at which stage of the disease increased ocular rigidity becomes manifest, longitudinal studies would be necessary.

In summary, we were able to show different in vivo changes in axial eye length after medically induced IOP 
lowering in patients with open-angle glaucoma compared to matched control patients. Our results suggest that ocular rigidity might be increased in eyes with primary open-angle glaucoma. Our non-invasive method for indirect measurement of ocular rigidity might be an additional tool for the diagnosis of glaucoma and shed new light on the pathogenesis of this common eye disease. However, to confirm our findings and verify methodical accuracy, further studies with larger numbers of patients and preferably more precise measurement of axial eye length will be needed. Accurate, simple and non-invasive methods for measuring ocular rigidity would make future investigations more effective and faster.

\section{Acknowledgements}

The authors would like to thank Carl Zeiss AG (Feldbach, Switzerland) for providing the IOL Master and Ziemer Ophthalmic Systems AG (Port, Switzerland) for offering us a PASCAL Dynamic Contour Tonometer at a reduced rate.

\section{Declared financial interests}

Ziemer Ophthalmic Systems AG (Port, Switzerland) offered us a PASCAL Dynamic Contour Tonometer at a reduced rate to conduct this study.

\section{References}

1 Collins R, van der Werff TJ. Mathematical Models of the Dynamics of the Human Eye. Vol. 34. Berlin: Springer, 1980; 29-38.

2 Friedenwald JS. Contribution to the theory and practice of tonometry. Am J Ophthalmol 1937; 20: 985-1024.

3 Silver DM, Geyer O. Pressure-volume relation for the living human eye. Curr Eye Res 2000; 20(2): 115-120.

4 Ytteborg J. The role of intraocular blood volume in rigidity measurements on human eyes. Acta Ophthalmol (Copenhagen) 1960; 38: 410-436.

5 Ytteborg J. Influence of bulbar compression on rigidity coefficient of human eyes, in vivo and encleated. Acta Ophthalmol (Copenhagen) 1960; 38: 562-577.

6 Eisenlohr JE, Langham ME, Maumenee AE. Manometric studies of the pressure-volume relationship in living and enucleated eyes of individual human subjects. $\mathrm{Br} \mathrm{J}$ Ophthalmol 1962; 46: 536-548.

7 Ytteborg J. Further investigations of factors influencing size of rigidity coefficient. Acta Ophthalmol (Copenhagen) 1960; 38: 643-657.

8 Ytteborg J. The effect of intraocular pressure on rigidity coefficient in the human eye. Acta Ophthalmol (Copenhagen) 1960; 38: 548-561.

9 Pallikaris IG, Kymionis GD, Ginis HS, Kounis GA, Tsilimbaris MK. Ocular rigidity in living human eyes. Invest Ophthalmol Vis Sci 2005; 46(2): 409-414.

10 Drance SM. The coefficient of scleral rigidity in normal and glaucomatous eyes. Arch Ophthalmol 1960; 63: 668-674.
11 Friedman E, Ivry M, Ebert E, Glynn R, Gragoudas E, Seddon J. Increased scleral rigidity and age-related macular degeneration. Ophthalmology 1989; 96(1): 104-108.

12 Pallikaris IG, Kymionis GD, Ginis HS, Kounis GA, Christodoulakis E, Tsilimbaris MK. Ocular rigidity in patients with age-related macular degeneration. Am J Ophthalmol 2006; 141(4): 611-615.

13 Pulido J. Scleral rigidity and macular degeneration: pathophysiologic or epiphenomenon? Am J Ophthalmol 2006; 141(4): 731-732.

14 Pavlin CJ, Burns PN, Foster FS. Use of microbubble ultrasound contrast agent to demonstrate the iris valve effect in human eye bank eyes. Am J Ophthalmol 1998; 126(5): 719-720.

15 Pitchon EM. How to measure the whole ocular rigidity? Am J Ophthalmol 2006; 142(4): 706-707; author reply 707.

16 Rose LT, Moshegov CN. Comparison of the Zeiss IOLMaster and applanation A-scan ultrasound: biometry for intraocular lens calculation. Clin Experiment Ophthalmol 2003; 31(2): 121-124.

17 Santodomingo-Rubido J, Mallen EA, Gilmartin B, Wolffsohn JS. A new non-contact optical device for ocular biometry. Br J Ophthalmol 2002; 86(4): 458-462.

18 Vogel A, Dick HB, Krummenauer F. Reproducibility of optical biometry using partial coherence interferometry: intraobserver and interobserver reliability. J Cataract Refract Surg 2001; 27(12): 1961-1968.

19 Cashwell LF, Martin CA. Axial length decrease accompanying successful glaucoma filtration surgery. Ophthalmology 1999; 106(12): 2307-2311.

20 Kook MS, Kim HB, Lee SU. Short-term effect of mitomycin$\mathrm{C}$ augmented trabeculectomy on axial length and corneal astigmatism. J Cataract Refract Surg 2001; 27(4): 518-523.

21 Nemeth J, Horoczi Z. Changes in the ocular dimensions after trabeculectomy. Int Ophthalmol 1992; 16(4-5): 355-357.

22 Francis BA, Wang M, Lei H, Du LT, Minckler DS, Green RL et al. Changes in axial length following trabeculectomy and glaucoma drainage device surgery. Br J Ophthalmol 2005; 89(1): 17-20.

23 Leydolt C, Findl O, Drexler W. Effects of change in intraocular pressure on axial eye length and lens position. Eye 2007; January 19 [E-pub ahead of print].

24 Drexler W, Findl O, Menapace R, Rainer G, Vass C, Hitzenberger CK et al. Partial coherence interferometry: a novel approach to biometry in cataract surgery. Am J Ophthalmol 1998; 126(4): 524-534.

25 Kaufmann C, Bachmann LM, Thiel MA. Comparison of dynamic contour tonometry with goldmann applanation tonometry. Invest Ophthalmol Vis Sci 2004; 45(9): 3118-3121.

26 Friedland BR, Mallonee J, Anderson DR. Short-term dose response characteristics of acetazolamide in man. Arch Ophthalmol 1977; 95(10): 1809-1812.

27 Sigal IA, Flanagan JG, Ethier CR. Factors influencing optic nerve head biomechanics. Invest Ophthalmol Vis Sci 2005. 46(11): 4189-4199.

28 Sigal IA, Flanagan JG, Tertinegg I, Ethier CR. Finite element modeling of optic nerve head biomechanics. Invest Ophthalmol Vis Sci 2004; 45(12): 4378-4387.

29 Bellezza AJ, Hart RT, Burgoyne CF. The optic nerve head as a biomechanical structure: initial finite element modeling. Invest Ophthalmol Vis Sci 2000; 41(10): 2991-3000.

30 Tengroth B, Ammitzboll T. Changes in the content and composition of collagen in the glaucomatous eye- -basis for a new hypothesis for the genesis of chronic open angle 
glaucoma - a preliminary report. Acta Ophthalmol (Copenh) 1984; 62(6): 999-1008.

31 Lam AK, Chan ST, Chan H, Chan B. The effect of age on ocular blood supply determined by pulsatile ocular blood flow and color Doppler ultrasonography. Optom Vis Sci 2003; 80(4): 305-311.

32 Malik NS, Moss SJ, Ahmed N, Furth AJ, Wall RS, Meek KM. Ageing of the human corneal stroma: structural and biochemical changes. Biochim Biophys Acta 1992; 1138(3): 222-228.

33 Nguyen CT, Bui BV, Sinclair AJ, Vingrys AJ. Dietary omega 3 fatty acids decrease intraocular pressure with age by increasing aqueous outflow. Invest Ophthalmol Vis Sci 2007; 48(2): 756-762.

34 Agrawal KK, Sharma DP, Bhargava G, Sanadhya DK. Scleral rigidity in glaucoma, before and during topical antiglaucoma drug therapy. Indian J Ophthalmol 1991; 39(3): 85-86.

35 Downs JC, Suh JK, Thomas KA, Bellezza AJ, Hart RT, Burgoyne CF. Viscoelastic material properties of the peripapillary sclera in normal and early-glaucoma monkey eyes. Invest Ophthalmol Vis Sci 2005; 46(2): 540-546. 